\title{
ALÉM DO RIO PSICOTERAPÊUTICO: REFLEXÕES ATUAIS SOBRE UMA EXPERIÊNCIA DE ACOLHIMENTO E INCLUSÃO
}

\author{
Beyond the Psychotherapeutic River: Welcomness and Inclusion
}

\author{
Anelize Teresinha da Silva Araújo ${ }^{1}$
}

LiliaFerreiraLobo ${ }^{2}$

\section{Resumo}

Tomando por base o relato de uma experiência desenvolvida no serviço de psicologia aplicada de uma universidade pública, este artigo tem como um de seus objetivos problematizar as condições de recepção, acolhimento e ação aos usuários adolescentes nos dispositivos de saúde, a partir de um balanço entre uma experiência de atendimento de um grupo de adolescentes realizada há 20 anos e as condições atuais. Certamente ocorreram mudanças nas práticas de atendimento em saúde mental durante esses anos. Mas teriam elas sido frutos apenas dos dispositivos das leis? Ou o que atualmente estamos consolidando teria por base o desconforto que muitos de nós, profissionais psi, sentiam em relação às práticas da época, assim como as experiências inovadoras?

Palavras-chave: Acolhimento; Dispositivos de saúde; Adolescência; Inclusão social.

\section{Abstract}

Starting off from the account of an experience developed at the applied psychology service of a public university, this article intends to address the conditions of reception and, welcomeness social inclusion of adolescent users in health apparatus, making a comparison between an experience of assistance of an adolescent group realized more than twenty five years ago and the current conditions. Certainly, there were changes in assistance practices throughout these years. However, would these changes be due only to legal regulations? Or does the situation we witness today have at its base, among several factors, the discomfort that many of us, professionals of psychology and psychiatry, felt regarding the practices of those times and which favored innovative experiences pregnant with intuition we had over twenty five years ago?

Keywords: Welcomeness; Mental health apparatus; Adolescence; Social inclusion.

\footnotetext{
Prof. ${ }^{a}$ Associada do Departamento de Psicologia da Universidade Federal Fluminense, Doutora em Psicologia Clínica, PUC-SP. Supervisora de estágio no CAPSi Monteiro Lobato, Niterói-RJ. e-mail: barateza@uol.com.br.

2 Prof. ${ }^{a}$ Associada do Departamento de Psicologia e do Programa de Pós-Graduação em Psicologia da Universidade Federal Fluminense. Doutora em Psicologia pela PUC-Rio. Coordenadora do Projeto: "Devir Criança: pesquisa de fontes para uma genealogia da criança anormal no Brasil, 1900-1940". e-mail: lferreiralobo@ig.com.br
} 


\section{Uma explicação necessária}

A que serve retomar um trabalho depois de muitos anos, principalmente, se considerarmos que propostas como a que iremos apresentar neste artigo já estão previstas em lei e vêm sendo gradativamente implementadas (muito mais lentamente do que desejaríamos) no âmbito dos atuais dispositivos da saúde mental e da educação? Contudo, insistimos que retomar um antigo trabalho pode servir à reflexão histórica, indicando, já naquela época, algumas "intuições", além de certo desconforto que sentíamos em relação às concepções de trabalho então predominantes. E mais: poderá servir para detectar questões que ainda hoje são problemáticas, como o acolhimento e a inclusão, sobremodo no campo da infância e da adolescência que entrelaça dispositivos de atendimento na saúde, educação, nas áreas jurídica e de lazer, dentre outras.

Questões tais como a recepção e o acolhimento aos usuários nos serviços de saúde e a tensão permanente no trabalho de equipes multidisciplinares parecem não ter fim e, apesar das diversas experiências e mudanças políticas nos últimos 20 anos, elas mantêm ainda o vigor de interrogação. Sabemos que, historicamente, a atenção dedicada às crianças e aos adolescentes pobres no Brasil privilegiou o dispositivo assistencial exercido principalmente por instituições religiosas e/ou filantrópicas, atualmente sob o signo das chamadas ONGs (organizações nãogovernamentais), encarregadas de cumprir as obrigações destinadas ao Estado, que por sua vez negligenciou as ações dirigidas àqueles sujeitos. Outras tensões nos perseguem desde sempre no campo da educação: o chamado "fracasso escolar", invariavelmente atribuído a problemas individuais, com diagnósticos clínicos de "hiperatividade" e "déficit de atenção" e a conseqüente medicalização pelo uso, em geral, indevido de remédios.

Atualmente, segundo a Organização Mundial da Saúde, ${ }^{3}$ apenas 10\% dos países têm ações para a infância e a adolescência. Vale lembrar que desde 1992, na II Conferência Nacional de Saúde Mental (Ministério da Saúde, 1994), os efeitos nefastos da institucionalização de crianças e jovens com transtornos mentais vêm sendo registrados e, em contrapartida, chama a atenção sobre a necessidade do desenvolvimento de políticas públicas que assegurem os direitos de cidadania e a inclusão de crianças e jovens no seio da sociedade, tanto quanto o desenvolvimento de pesquisas e de tratamentos que produzam impactos positivos na área clínica. Ainda em 1994, o Congresso Mundial sobre Necessidades Educativas Especiais na Espanha emitiu a Declaração de Salamanca ${ }^{4}$, propondo normas sobre a igualdade de oportunidades para pessoas com deficiência, por meio de medidas como a inclusão social e inclusão em classes regulares de ensino.

A Constituição de $1988^{5}$, que passou a considerar a criança e o adolescente como sujeitos de direitos e de responsabilidades compatíveis com suas capacidades, e a Convenção Internacional pelos Direitos da Infância, em 1989, ${ }^{6}$ desencadearam o processo que culminou na regulamentação do Estatuto da Criança e do Adolescente, em 1990.

O movimento que, por mais de duas décadas lutou pela reforma psiquiátrica, a III Conferência de Saúde Mental em 2001, ${ }^{7}$ e a Lei n ${ }^{\circ}$. 10.216, de 6 de abril de 2001, ${ }^{8}$ indicam a importância de políticas públicas, na área de saúde mental, que atendam satisfatoriamente às crianças e aos adolescentes. Tais políticas se articulariam em redes conectando diferentes setores voltados para a inclusão das crianças e dos jovens, garantindo-lhes saúde e melhores condições de vida.

Portanto, há 25 anos, foi no vazio de legislações e referenciais que respondessem positivamente aos problemas das crianças e dos jovens, e julgando insatisfatórios os modelos de atendimento forjados sobre paradigmas já naquela época por nós questionados, que empreendemos a

\footnotetext{
Organização Mundial de Saúde: http://www.who.int/en/. Consulta realizada em 17 de março de 2008.

4 Declaração de Salamanca sobre princípios, política e prática em educação especial: http://www.cdipod.org.br/salamanca.htm. Consulta realizada em 17 de março de 2008.

Constituição da República Federativa do Brasil de 1988: http://www.planalto.gov.br/ccivil_03/Constituição. Consulta realizada em 17 de março de 2008.

6 Convenção Internacional dos Direitos da Criança: http://www.promenino.org.br/Conteudo/tabid/77/ConteudoId/c. Consulta realizada em 17 de março de 2008.

III Conferência de Saúde Mental em 2001: http://www.saudemental.med.br/IIIC.htm. Consulta realizada em 17 de março de 2008.

8 Lei 10.216, de 6 de abril de 2001, também conhecida como Lei Paulo Delgado: http://pt.wikipedia.org/wiki. Consulta realizada em 17 de março de 2008 .
} 
experiência de trabalho ora apresentada para alguma reflexão. A opção pela manutenção do título original não é por acaso. Foi devido ao fato de considerarmos que um serviço, além de existir para o tratamento do usuário, ele existe para acolhê-lo. Trata-se de: “... uma resposta social a fenômenos clínicos, a certos estados da psicose, a certas passagens ao ato, a alguns estados de depauperamento físico, que podem levar o sujeito à exclusão social absoluta e até a morte" (Zenoni, 2000, p. 14-15).

Há vinte e cinco anos propúnhamos uma forma de atendimento inclusiva (embora não usássemos explicitamente este termo) e que fosse além de uma proposta clínica ou pedagógica, inspirada na experiência de Maud Mannoni (1978, p. 17), "Um lugar para viver”. É a autora quem nos esclarece:

São acolhidas em Bonneuil num lugar que é um "lugar de vida", junto de pessoas que não se interrogam nunca sobre o que é a doença mental, sobre o que é ser uma criança surda ou débil; não mais se sabe quem é "louco" e quem não é. O facto de permanecer aí transitoriamente permite a cada um chegar a descobrir-se face ao que desejaria ser, e a maneira como uns e outros saem de Bonneuil é extremamente diferente.

\section{O início do trabalbo}

A experiência sobre a qual trabalharemos foi realizada no início dos anos 80 no Serviço de Psicologia Aplicada (SPA) da Universidade Federal Fluminense. Naquela ocasião, a recepção aos usuários era feita por meio de triagem a partir da qual os casos eram encaminhados para equipes específicas: as que atendiam adultos e crianças. Muitos impasses ocorriam neste tipo de recepção. Acontecia demasiado tempo de espera para atendimento entre a triagem e o atendimento. Devido ao grande número de usuários nesta situação, supervisores e estagiários passavam a escolher os casos a serem atendidos, o que acarretava a exclusão tácita de muitos do SPA."Peregrinos de lugar nenhum" (Couto, 2001, p. 2) foi com eles que nos deparamos.

Certo dia apareceu para triagem, levado pela mãe, um rapaz? Um menino? Ele tinha 17 anos, corpo de uma criança de 9 e parecia agir como uma criança de 7 anos. Isso poderia não ser nada se cada história pudesse ser contada sem grandes embaraços. Aconteceu, no entanto, que nos embaraçamos ao ouvir sua história. Perguntas: seria necessário atendê-lo? Seria possível? Além disso, o que fazer com aquele jovem que já havia percorrido vários lugares na cidade em busca de atendimento sem encontrar acolhimento até então? $\mathrm{Na}$ mesma semana, um colega que fazia a triagem recebeu uma jovem portadora de síndrome de Down em busca de atendimento. Também nós, no SPA, tínhamos por hábito derivar este tipo de caso para outros serviços. Contudo, sentimo-nos premidos a fazer alguma coisa e questionar nossos próprios modelos de trabalho: era necessário inventar outra modalidade para este tipo de clientela e tentar interferir no campo social.

Juntando-nos a outras colegas do SPA, que em suas áreas de trabalho experimentavam desconforto semelhante, formamos a equipe de trabalho assim constituída: uma psicóloga da área de clínica, uma assistente social, uma psicóloga escolar com experiência de trabalho com os portadores de necessidades especiais (ambas professoras do Departamento de Psicologia) e uma estagiária do Curso de Psicologia. Após o levantamento dos casos à espera de atendimento, verificamos um grande número de adolescentes até então "não classificáveis" e que, por isso, seriam excluídos do atendimento: foi a eles que nos dedicamos. ${ }^{9}$ O ponto de partida da equipe foi o interesse em fazer um trabalho que integrasse as áreas de psicologia clínica e escolar, certas já naquela época, de que a divisão em áreas com que trabalhávamos não era adequada aos novos desafios que pretendíamos enfrentar. ${ }^{10}$ Após algumas reuniões nas quais discutimos a filosofia, o planejamento, a viabilidade e a execução do trabalho, chegamos a poucas conclusões e a muitas dúvidas. Examinando os casos dos adolescentes que aguardavam atendimento, constatamos que havia muitos outros que não teriam um lugar dentro dos trabalhos instituídos no SPA. Verificamos traços comuns entre eles: a mesma faixa etária, evidente atraso de escolaridade, sendo que alguns com suspeita ou evidência de deficiência mental ${ }^{11}$, dependência

\footnotetext{
Trata-se dos primeiros adolescentes integrantes do grupo.

10 Uma modalidade de trabalho até então não tentada e que hoje se aproximaria de uma abordagem interdisciplinar.

11 Como não trabalhávamos com psicodiagnóstico, não nos interessávamos pelas separações instituídas, preferimos formar um grupo misto, no qual a deficiência não era critério para a formação do grupo em questão. Pensávamos em multiplicar encontros, dentro e fora da sala de atendimento, o que hoje pode ser considerada uma estratégia de inclusão.
} 
familiar, isolamento social e dificuldades na aquisição de comportamentos autônomos, o que acabou por se tornar critérios para a constituição de um grupo. A evidência ou não da deficiência mental, como o caso da adolescente com síndrome de Down e do rapaz de 17 anos que não havia atingido a puberdade, não foram as principais indicações para a formação do grupo. Pretendíamos um trabalho que valorizasse as positividades de cada membro, afastando os rótulos das deficiências. "A função dos laudos é, pois, a de responder a necessidade social de classificação dos desviantes, mais do que auxiliar na tarefa de recuperação a que se propõem" (Lobo, 1992, p. 120).

Após entrevistar os adolescentes e seus responsáveis, propusemos formar um grupo limitado a oito adolescentes, e outro constituído por seus pais e/ou responsáveis.

Os objetivos eram: 1. Quanto aos adolescentes: abordar as relações de interdependência mãe-filho e adulto, facilitar a aquisição de laços grupais de modo a desenvolver funções de autonomia dentro do próprio grupo, promover a conquista de formas independentes de inserção no mundo. 2. Quanto aos pais e/ou responsáveis: facilitar a independência destes em relação a seus filhos; auxiliá-los na ação e aceitação da singularidade de seus filhos. Sobre este último grupo, por sua curta duração, não compôs o relato de nossa experiência.

Passaremos a apresentar partes do texto original desta experiência, com pequenas alterações, já que se trata agora de adaptá-lo ao novo formato de um artigo.

\section{Além do rio psicoterapêutico: reflexões inconclusas acerca de nossos objetivos}

Geografia não é simplesmente geografia, um mapa. Os rios, por exemplo, nos ensinam a criar lugares. Os rios também não dependem de lugar físico, correm criando história. Assim também as pessoas fazem suas histórias, marcam seus lugares

Pretendemos contar a história de um grupo de pessoas, fontes de águas distintas que, ao se encontrarem, caminham por ora na direção do oceano. Inicialmente, éramos equipe com muita disposição e alguma reflexão crítica sobre o que não queríamos fazer. Isso pode parecer pouco para um trabalho que se pretendia sério, mas era com o que contávamos. Reunimo-nos, outras fontes apareceram, as margens deste rio novo ampliaram-se.

Voltando aos afluentes, os primeiros adolescentes integrantes do grupo, até então isolados. Compreendemos que ter 17 anos, tamanho de 9 e agir como se tivesse 7 é por demais turbulento para uma fonte só. Por outro lado, como deve ser difícil para uma pequena poça viver à espera de outras águas para não ser simplesmente secada pelo sol. E os novos chegaram, juntando-se às duas fontes: uma tímida, sem saber por onde escoar, insegura de seguir sozinha; outra prestes a romper em águas maduras, preocupada em não provocar enchentes, temerosa de enraivecer oceanos. Outro afluente surge tão pacato, posto que até então outro jeito não havia, mas o que ninguém sabia era de sua maior tristeza. Mas apesar de frio e fino, este rio fazia marola. Finalmente, outro que chegou gordo e forte, parecendo velho e cansado, já querendo morrer, aterrar em qualquer margem, ficou lá no fundo. $\mathrm{O}$ que se encontra lá no fundo do rio? Lá é onde moram os peixes, plantas e corais, tantas magias mais - o que se traz de acúmulo são muitas belas histórias, muitas lendas verdadeiras, e o carinho maior das águas serenas que acolhem toda a gente.

Como leito desse rio servia a idéia, há muito delineada por Maud Mannoni (1978) - “ um lugar para viver" - antes de tudo, um lugar de convivência. Como margens desse rio nossas experiências anteriores. Como fluxo servia o processo de interação criado pelo grupo de profissionais, pais e adolescentes inicialmente represados nos esquemas sociais. Como oceano a atingir, tudo que está lá fora: a escola, a rua, o correio, o ônibus, o mundo.

O que existia em comum entre os adolescentes do nosso grupo? Mais ou menos presos da armadilha do rótulo social da deficiência ou da inadequação, todos passaram pela experiência do fracasso: não só o escolar, mas num sentido muito mais amplo, o fracasso do próprio crescimento, o de tornar-se adolescente. E a escola, como instituição de exclusão social no Brasil, foi uma das responsáveis por este processo de paralisação.

Embora nem sempre estejam de acordo, família e escola às vezes se aliam quando se trata de domesticação de suas crianças. Principalmente no que diz respeito ao modelo de família nuclear burguesa, que se não é o único, é ainda muito forte e cujos comportamentos, valores e aspirações são também impostos pela escola. Neste sentido, J. 
Donzelot adverte-nos que a família não é a instituição onde se instalam as forças sociais conservadoras. "A família, como objeto, oculta-se num outro: 'o social', do qual ela é rainha e prisioneira" (Donzelot, 1980, p. 13).

A escola, passando a assumir em grande parte a educação das crianças, foi um veículo importante da implantação da nova ordem social burguesa. Caso a criança consiga passar por todas as normas, do fracasso da reprovação, da recuperação, da repetência e do não aprender, além dos diagnósticos psicopedagógicos, das prescrições médicas e psicoterápicas, ela poderá passar despercebida e se firmar como cidadão comum. Caso contrário, sua história não mais lhe pertencerá, mas aos relatórios dos conselhos de classe e dos diagnósticos dos demais especialistas.

Eis a realidade de nossos adolescentes: a eles foi negada a própria história, paralisados no tempo, endurecidos de uma infantilização permanente. E nos foi difícil lidar com isso, libertarmo-nos do olhar que nos aprisiona e vê-los plenos de vida: desenvolver em nós mesmas uma atitude inspiradora de criatividade e de quebra da hierarquia que, em geral, instala-se na relação adolescente-adulto. Acreditamos que o ponto fundamental para gerar tal clima seria o prazer que pudéssemos experimentar realizando o trabalho, onde não funcionaríamos a distância dos adolescentes, procurando seguir a correnteza do fluxo do rio dos acontecimentos grupais. Talvez por força deste nosso entusiasmo, tivemos, no começo, dificuldades em não assumir uma atitude diretiva, frente à apatia inicial do grupo. E em discernir até que ponto o grupo pode "pegar carona" no entusiasmo dos adultos ou ser sufocado pelo desejo destes, como nos sugere Maud Mannoni (1976, p. 41). Uma atitude classicamente psicoterapêutica de não envolvimento nas brincadeiras e movimentos grupais nos deixaria a salvo desta questão. Seriam eles os pacientes e nós os terapeutas. Uma funda separação aí se perpetuaria, o que poderia servir a outros objetivos, não aos nossos. Mas, se nos afastamos das classificações dos diagnósticos, afastamo-nos também da loucura e dos desvios dominados por essas classificações. Práticas divisoras conforme Foucault (1977), cujos efeitos de poder produzem descriminações e separações segregadoras no campo social.

Por isso, optamos por trabalhar sem o código preestabelecido de uma determinada técnica, o que não significa a exclusão do rigor de uma gramática, não aquela de uma ordem sob o domínio do mundo das idéias, mas uma gramática colada no mundo, inscrita ao mesmo tempo nos nossos corpos, nas nossas práticas, nos nossos saberes, entendendo-se também que este tipo de consideração pretende uma intervenção, por pequena que seja, sobre a cultura psi dominante.

Somos cabeças formadas por idéias, palavras separadas das coisas. Difícil introduzir uma prática que subverta em nós mesmas esta ordem. Muitas vezes nos indagávamos sobre a apatia inicial dos adolescentes, quando estávamos tão cheias de "boas intenções". Não queríamos buscar causas externas à situação grupal a fim de justificar as dificuldades. Brincávamos com o que nós adultos queríamos ou com o que eles gostavam? Eram indagações que percorriam nossas reflexões. O grupo logo nos respondeu, introduzindo uma brincadeira que durou várias sessões e que consistia em representar uma novela elaborada por eles, limitando gradativamente nossa intromissão na sua autonomia. Nossa atitude passou, então, a ser mais instigadora e menos diretiva e, em conseqüência, o grupo passou a imprimir uma direção própria ao curso do rio. $\mathrm{O}$ aparecimento da novela fixou um marco no desenvolvimento do grupo e em cada uma de nós, acontecimento a que nos referiremos mais adiante.

$\mathrm{O}$ que pretendemos com este trabalho? Nossa proposta é a de criar um espaço alternativo não estritamente pedagógico ou terapêutico, visando intensificar, o mais possível, um clima espontâneo e emocionalmente denso de brincadeiras e experiências grupais a que os adolescentes em geral têm acesso. Um lugar de partilha que não pretende substituir o trabalho pedagógico da sala de aula, ou da psicoterapia. Contudo, temos observado efeitos pedagógicos e/ou terapêuticos:

- Alguns membros do grupo aprenderam a lidar com dinheiro, uma aprendizagem iniciada na brincadeira de mercado, no registro da contabilidade da caixinha, onde cada um colabora com o que puder para a compra de material, para financiar as passagens de ônibus dos que não podem pagar, quando de nossas saídas.

- Todos os adolescentes, guardando suas peculiaridades, vêm apresentando mudanças mais ou menos nítidas de atitudes perante a vida. Em F., o autor do roteiro e diretor da novela, a riqueza imensa de suas águas profundas emergiu, antes afundadas no escuro da solidão, do silêncio e da falta de vontade de viver. 
Nosso trabalho não tem finalidade normativa, no sentido de um condicionamento à sociedade dita normal e ditadora de um modelo monolítico de normalidade, como se ela fosse em si mesma um bem, um sistema onde os indivíduos se acham aprisionados ou se deixam aprisionar porque não conseguem inventar outra saída, a não ser o do sintoma (Canguilhem, 1978). Como trabalho que não se propõem objetivos estritamente terapêuticos, não se utilizam técnicas de interpretação ou de clarificação. Procuramos também evitar as centralizações, numa tentativa de romper as estratificações dentro do grupo, principalmente entre terapeutas e pacientes. Isso significa que, trabalhando com as diferenças, mesmo reconhecendo aquelas que nos marcam como adultos, o grupo possa transformar-se, não num lugar de reprodução das hierarquias do mundo social, mas em alianças geradoras de expansão e autonomia, forças que possam atravessar também a nós, os adultos.

O grupo de adolescentes acontecia uma vez por semana, em sessão de hora e meia, inicialmente com a presença de três de nós, num revezamento em que uma dentre as quatro coordenava no mesmo horário, em outra sala, o grupo de responsáveis ${ }^{12}$. Assim o grupo de adolescentes não tinha sempre a mesma coordenadora, já que era nosso objetivo permitir que os vínculos mais fortes se fizessem entre os jovens, até que pudessem reunir-se sem a nossa presença, o que na realidade aconteceu uma vez, quando ocuparam a sala e solicitaram que aguardássemos para entrar. Buscávamos a troca de experiências e a oportunidade de estabelecer novos encontros.

Éramos três no grupo de adolescentes e, portanto, nem sempre as mesmas três, na tentativa de evitar não só a dependência do grupo a uma única coordenadora, como atender as diferenças manifestadas dos componentes, quando o consenso em torno de um objetivo não fosse possível. É que o grupo, que parecia ter traços comuns, estava pleno de singularidades que, se não fossem atentamente trabalhadas, corriam o risco de retornar às condições de isolamento em que viviam seus membros no espaço social maior.

Uma vez por mês fazemos sessões externas com os adolescentes, que duram em torno de 3 horas, com a participação das quatro coordenadoras. A finalidade desses passeios era criar a oportunidade para que se defrontassem, direta e espontaneamente, com situações reais, para que enfrentassem, com o mínimo de interferência nossa, situações do tipo: atravessar as ruas, lidar com dinheiro, pedir informações, respeitando as condições de cada um.

Em termos de coordenação, tivemos três momentos: o primeiro em que cada sessão era planejada anteriormente, sendo uma de nós mais diretamente responsável pela coordenação e as demais funcionando como colaboradoras; o segundo em que optamos por uma coordenação comum, levando algumas atividades previamente selecionadas; o terceiro em que integramos os dois momentos anteriores e deixamos emergir o interesse grupal, quando então intervínhamos participando no que o grupo inventasse.

Estas modificações no estilo de coordenação se deram por conta das dificuldades que tivemos, tanto por estarmos aprendendo a trabalhar juntas num grupo, como frente à questão $\mathrm{da}$ continuidade $\mathrm{X}$ descontinuidade dos movimentos grupais (aliás, estas questões ainda permanecem, com aspectos diferentes, como objeto de nossas discussões). Propúnhamos atividades e não sabíamos como não sermos diretivas se eles se colocavam passivos diante de nós, reproduzindo talvez o que acontecia em suas demais relações. Mesmo nestas condições iniciais, o grupo conseguiu criar: a princípio as atividades giravam em torno de trabalho com sucata, música, marionetes e elaboração de histórias. As dramatizações com marionetes, por exemplo, tiveram bastante significado para um dos adolescentes que, por meio de um personagem por ele inventado, pôde expressar-se no grupo.

Uma das adolescentes utilizava a atividade perseverativa de folhear revistas como modo de se isolar. Ocupava-se o tempo todo das sessões em olhar e recortar figuras de revistas da caixa de material que levávamos para sala. Primeiro decidimos retirar as revistas da caixa antes das sessões, depois resolvemos aproveitar seu interesse por figuras numa atividade grupal. Passamos todos a recortar figuras de nossa preferência e a dramatizar em nossos corpos como as sentíamos. Depois sugerimos ao grupo que organizasse uma seqüência

\footnotetext{
12 Este grupo teve curta duração e por isso não será objeto deste trabalho.
} 
com elas e construísse, assim, uma história na tentativa de conectar as estampas. Observamos que, embora pretendêssemos criar uma história comum, cada componente preocupava-se com a história de sua figura, desprezando, na maioria das vezes, o nexo entre elas.

Notamos os primeiros passos de colaboração no trabalho com sucata, quando passaram a dar sugestões uns aos outros. $\mathrm{Na}$ brincadeira de loja, vários papéis (freguês, vendedor, caixa) foram experimentados, além da oportunidade de aprender o uso do dinheiro.

Ao percebemos o grupo estereotipado com algumas posturas corporais rígidas, introduzimos alguns trabalhos de corpo, que permitiram maior descontração e o aparecimento do tema da sexualidade. Isso coincidiu com um episódio, num dos passeios, quando o grupo presenciou o exame, por um veterinário, de uma cabra grávida no Horto. A situação da gravidez e do parto foi levantada por uma das adolescentes na sessão após o passeio, quando utilizamos a leitura de dois livros. ${ }^{13}$ Inicialmente bastante embaraçados, acompanharam atentamente, sem muitos comentários. Tínhamos dúvidas a respeito de qual seria a reação das mães, se havíamos interferido abusivamente na educação de seus filhos. Ao contrário de nossas expectativas, elas respiraram aliviadas por termos passado para eles informações que elas não saberiam como lhes dar.

Daí em diante, certos interesses passaram a emergir. Numa sessão em que falávamos sobre as aspirações de cada um, um adolescente falou de sua vontade de ser escritor, de escrever programas para a TV. Pedimos, então, que escrevesse alguma coisa, uma programação para o grupo, por exemplo. Ele resolveu fazer uma novela, representada por todos e dirigida pelo autor. Este foi, talvez, o momento da maior criatividade do grupo - a história, seu desenvolvimento e as características de seus personagens constituíam-se numa autêntica análise de grupo. Foi a oportunidade em que os adolescentes melhor colocaram seus sentimentos em relação a eles mesmos e a nós. Instalou-se assim um clima que nos possibilitou entender nossa posição no grupo e o papel que desempenhávamos. Esta nova atividade, que durou várias sessões, constituiu-se num marco no desenvolvimento grupal, num momento de ação e interação, de maiores trocas entre nós coordenadoras e entre nós e os adolescentes. O capítulo final da novela, no último dia do nosso contrato (renovado depois por mais um semestre), o grupo fez acontecer a separação do casal protagonista da novela, inicialmente dolorosa e depois amistosa. Uma de nós, no papel de empregada doméstica, recebeu ao final uma vultosa herança, que entendemos não apenas como um agradecimento, mas como um meio de nos mostrar a riqueza que eles colocaram em nossas mãos.

Os momentos de decisão sempre foram os mais difíceis. Num deles, quando se instalou a indecisão frente à escolha do lugar que visitaríamos no próximo passeio, surgiu o tema do crescimento. Vários recursos o grupo utilizou para que nós, os adultos, assumíssemos a escolha: do silêncio à chantagem emocional do tipo: "vocês não são boas para nós". Em momentos como este ficava bem claro o quanto haviam renunciado ao seu próprio crescimento. Um dos adolescentes, talvez o mais paralisado no mito de uma infantilização permanente e o mais velho cronologicamente, reagiu de forma intensa, primeiro tapando os ouvidos para não participar da discussão e depois saindo abruptamente da sala. Mostramos ao grupo e ao próprio (quando retornou) que sua saída fora também uma decisão e que nestas e em outras situações o grupo fora capaz de tomar decisões e que não gostava quando uma de nós invadia sua autonomia, embora dificilmente protestasse de forma direta. O tema do crescimento ultrapassou aquela sessão e se prolongou no passeio, nas observações frente ao comportamento infantilizado de uma das adolescentes que faltou por não andar sem a companhia da "mamãe".

Nos passeios, tentávamos estimular-lhes a iniciativa, tomando informações nos correios, por exemplo, quando o grupo resolveu escrever cartas aos faltosos, falando do prejuízo de suas ausências. Da mesma forma, nos ônibus, quando insistíamos que conferissem o troco, prestassem atenção no caminho de ida e de volta, assim como a hora de descer. Desencorajávamos o andar de braço dado, alertando para os referenciais que encontrávamos: fluxo dos carros, lugares adequados para atravessar a rua, mão e contra- mão, sinais de trânsito, buracos,

13 Trata-se de dois livros de Peter Mayler: “O que está acontecendo comigo?” São Paulo, Mosaico, 1975 e “De onde viemos?” São Paulo, Mosaico, 1980. Ainda hoje são utilizados nas escolas. 
propagandas, número e cor dos ônibus que nos serviam, etc. Observamos nos últimos passeios maior descontração, independência, busca de novas experiências, assim como atitudes de carinho e proteção entre eles.

\section{Algumas considerações sobre um trabalbo (que estava em andamento)}

Continuamos sensibilizadas por nossas questões primeiras: instigar momentos propiciadores de autonomia, expandir o poder de maneira que ele circule e desenvolva relações em que todos participem. Estes foram temas que percorreram tanto o grupo de adolescentes, quanto a nós coordenadores, nas sessões coletivas de reflexão que realizamos logo após o término do grupo. ${ }^{14}$ Temos certeza de que, mesmo após estas sessões, não conseguimos apreender toda a rede de implicações que esse trabalho nos suscitou, face à sua característica interdisciplinar e à nova modalidade de atendimento que se constituiu no Serviço de Psicologia Aplicada de nossa Universidade.

Desde a elaboração deste trabalho, pretendíamos levá-lo às instituições escolares de onde provieram nossos adolescentes e que, com freqüência, encaminham-nos crianças e jovens ditos especiais para tratamento, como que renunciando talvez à tarefa de educar e/ou refletir criticamente sobre as questões institucionais das práticas escolares. Portanto, pretendemos ainda levar adiante a discussão deste trabalho acerca de nossos objetivos, no âmbito social e político da função da escola. ${ }^{15}$

Considerações finais vinte e cinco anos depois: por uma ética do conhecimento

Esta modalidade de trabalho com grupo de adolescentes continuou, sob a coordenação de uma de nós, com a participação, a cada ano, de estagiária do Curso de Psicologia, a partir de meados de 1984 até dezembro de 1988, data de seu término. Foram, portanto, mais quatro anos e meio de trabalho cujos acontecimentos grupais não caberiam no espaço de um único artigo. Em poucas palavras, pode-se dizer que continuou sendo um trabalho fascinante para a sua coordenadora que viveu nesses anos transformações no grupo e em si mesma.
Ressalte-se que, apesar de singelo, foi um trabalho pioneiro que, à luz da experiência de Bonneuil, desconsiderou os diagnósticos, as classificações instituídas, passando a trabalhar segundo critérios pontuais de não separação em espaço reservado às deficiências, embora ainda agrupasse os jovens segundo "atraso evidente de escolaridade". Mas seus objetivos não se dirigiam à "recuperação" deste atraso, mas aos efeitos perniciosos que a exclusão havia perpetrado em suas vidas. Experiência um tanto anárquica, no sentido político do termo, cujos princípios vinham sendo encampados, desde a década de 70 , por autores considerados pós-estruturalistas como Foucault, Deleuze e os criadores das ferramentas de intervenção da Análise Institucional, como René Lourau, George Lapassade e Felix Guattari, dentre outros, assim como anteriormente por Maud Mannoni, a quem poderíamos hoje denominar como uma lacaniana institucionalista.

Atualmente, após a conquista da Reforma Psiquiátrica, o Brasil mantém 78 CAPSIs, Centros de Atenção Psicossocial para a Infância e Adolescência, sendo 14 no estado do Rio de Janeiro ${ }^{16}$. Uma das principais demandas aos serviços neste Estado é composta por crianças portadoras de necessidades especiais, as com dificuldades ou distúrbios de aprendizagem e, sobretudo, aquelas consideradas de risco social, o que demonstra que as questões de inclusão têm se revelado muito mais complexas do que a princípio os serviços puderam prever. No caso da escolarização, não se trata simplesmente de incluir essas crianças nas classes regulares como se a inserção em outro espaço físico abolisse automaticamente os efeitos da exclusão. A complexidade das questões sobre a infância e a adolescência no mundo contemporâneo indica a obrigatoriedade de progredirmos na intervenção na cultura dos procedimentos dissimuladamente discriminatórios.

Cuidados e saberes especializados continuam sendo necessários e precisam ser dispensados pelas escolas. Não se pode pensar que incluir em classes regulares, por exemplo, crianças autistas, cegas, surdas ou portadoras de síndrome de Down não signifique um tipo de formação profissional para cada uma dessas diferenças, como

14 Este texto foi em parte extraído do diário que cada uma de nós se incumbia de elaborar e discutir nas sessões de reflexão coletiva.

15 Por diversos motivos (principalmente pelo fato da quase totalidade dos adolescentes já se terem desligado da instituição escolar) não conseguimos levar adiante esta proposta.

16 Em vista da criação de novos CAPSis considerando a diminuição da relação entre o número de habitantes no território e a necessidade de acolhimento: a relação muda de 1 CAPSi para cada 200 mil para 1 CAPSi para cada 1000 mil. 
também a elaboração de novos projetos, recursos e processo de trabalho. Crianças surdas, por exemplo, precisam de professores que saibam a língua de sinais, crianças cegas do método de alfabetização em Braille, além de procedimentos didáticos adequados a cada tipo de deficiência. Do mesmo modo, guardando as características próprias, no trabalho da clínica. Além disso, a questão, além da especialização, é ética. Acolhimento e inclusão não são simples respeito às diferenças, o que pode implicar em novas formas de abandono. É saber trabalhar com elas e aprender com elas, é saber fazer uso de todos os recursos disponíveis na direção que elas, sujeitos, nos apontam. Isso requer uma ética da criação e do conhecimento. Embora nosso grupo não pretendesse ser um lugar de tratamento e de educação, o que significava o afastamento destas especificidades, os saberes que estavam em jogo foram sempre objeto de reflexão ética.

Por ocasião de um levantamento feito em 2000 pela Secretaria de Saúde, havia cerca de 832 crianças e adolescentes vivendo em abrigos para deficientes no estado do Rio de Janeiro, "submetidos à lógica mortificante da institucionalização e excluídos do sistema formal de saúde" (Couto, 2001, p. 8). Por outro lado, "outras tantas crianças e adolescentes diagnosticadas como autistas e psicóticas são encontrados peregrinando em busca de atendimento..." (Couto, 2001, p. 2). Eis a questão que permanece: a quem cabe o acolhimento a esses casos?

[...] peregrinos de lugar nenhum? [...] acabam por se verem submetidos a métodos pedagógicos de controle de suas condutas bizarras, ou ainda, à excessiva medicalização, com conseqüências devastadoras para as sua existências. Não raramente ainda depara-se com um contingente significativo da clientela infanto-juvenil [...], portadoras de diagnóstico de 'distúrbio de aprendizagem' ou 'distúrbio de conduta' [...], superlotando os ambulatórios públicos que frequentemente as absorvem sem problematizar esta demanda (Couto, 2001, p. 8).

A esse respeito, a mesma autora, Maria Cristina Ventura Couto (2002), ao mencionar a Portaria n. 336/2002, do Ministério da Saúde, que instituiu os Centros de Atenção Psicossocial
Infanto-Juvenis (CAPSI) em todo território nacional, destaca a importância da formação de redes para o atendimento desta clientela. Já em 1969, era esta a proposta de Maud Mannoni para Bonneuil, mesmo caminhando ao largo das políticas oficiais de saúde mental na França: a rede de amigos de Bonneuil como um dispositivo fundamental para a desinstitucionalização de crianças e adolescentes e que ia além das instituições e de saberes especializados, incluindo os chamados agentes leigos da sociedade (Mannoni, 1976). Trata-se de dispositivos extraclínicos, que hoje estão gradativamente em formação e que se podem constatar no estado do Rio de Janeiro. Assim nos revela Maria Cristina Ventura Couto $(2002 \text {, p. } 3)^{17}$, "não há campo discursivo, campo de especialidade ou campo de ações que esgotem em si todas as respostas, daí, a tão cara noção de rede". Tal como na experiência de Bonneuil, a rede pode desenvolver dispositivos de suporte à desinstitucionalização de crianças e adolescentes. Isto se conseguir efetivamente

[...] rever com os ambulatórios da rede de saúde seus projetos institucionais de atendimento para crianças, discutir casos em conjunto, repensar a clínica e tudo mais que se insere nesta perspectiva de formar rede, lembrando sempre que esta rede também precisa escapar da armadilha de se oferecer como total. Sempre haverá o que não se sabe ainda. Construir rede me parece, fundamentalmente, suportar que não se sabe e não se pode tudo (Couto, 2002, p. 5).

\section{Referências}

Brasil. Constituição da República Federativa do Brasil de 1988. Constituição. Recuperado em 17 de março de 2008, da Presidência da República: http:/ /www.planalto.gov.br/ccivil_03/Constituição

Brasil. Lei 10.216 de 6 de abril de 2001. Recuperado em 17 de março de 2008: http:// pt.wikipedia.org/wiki

Canguilhem, Georges. (1978). O normal e o patológico. Rio de Janeiro: ForenseUniversitária.

\footnotetext{
17 Coordenadora do Fórum Inter-Institucional para Atendimento em Saúde Mental de Crianças e Adolescentes da Assessoria de Saúde Mental da Secretaria Estado de Saúde do Rio de Janeiro, até 2006.
} 
Convenção Internacional dos Direitos da Criança.

Recuperado em 17 de março de 2008: http:// www.promenino.org.br/Conteudo/tabid/77/ ConteudoId/c

Conferência de Saúde Mental em 2001: Controle social. Recuperado em 17 de março de 2008: http://www.saudemental.med.br/IIIC.htm

Couto, Maria Cristina Ventura. (2001). Novos desafios à reforma psiquiátrica brasileira: necessidade de construção de uma política pública de saúde mental para crianças e adolescentes. Cadernos de Textos da III Conferência Nacional de Saúde Mental, (p. 111), Brasília.

Couto, Maria Cristina Ventura. (2002, dezembro) Trilhando novos caminhos: a política pública de saúde mental para crianças e adolescentes. Texto apresentado na II Jornada de Saúde Mental Infanto-Juvenil, organizada pelo CERSAMiBetim (mimeo).

Declaração de Salamanca sobre princípios, política e prática em educação especial. Recuperado em 17 de março de 2008: http://www.cdipod.org.br/ salamanca.htm

Donzelot, Jacques. (1980). A polícia das famílias. Rio de Janeiro: Graal.
Foucault, Michel. (1977). Vigiar e punir. Petrópolis: Vozes.

Lobo, Lilia Ferreira. (1992). Deficiência: prevenção, diagnóstico e estigma. In: H. C. B, Rodrigues, B. Leitão, \& R. B. Barros (Org.), Grupos e instituições em análise. Rio de Janeiro: Rosa dos Tempos.

Mannoni, Maud. (1976). Educação impossível. Lisboa: Moraes.

Mannoni, Maud. (1978). Um lugar para viver. Lisboa: Moraes.

Ministério da Saúde (1994). Relatório final da II conferência de saúde mental, 1992, Brasília.

Organização Mundial de Saúde. Recuperado em 17 de março de 2008: http://www.who.int/en/

Zenoni, A.(2000). Psicanálise e Instituição: a segunda clínica de Lacan: Abrecampos. Revista de Saúde Mental do Instituto Raul Soares, 1(1), 36-47.
Recebido em: 30/07/2007

Received in: 07/30/2007

Aprovado em: 20/10/2007

Approved in: 10/20/2007 